輯六十第誌雜會醫獸英中

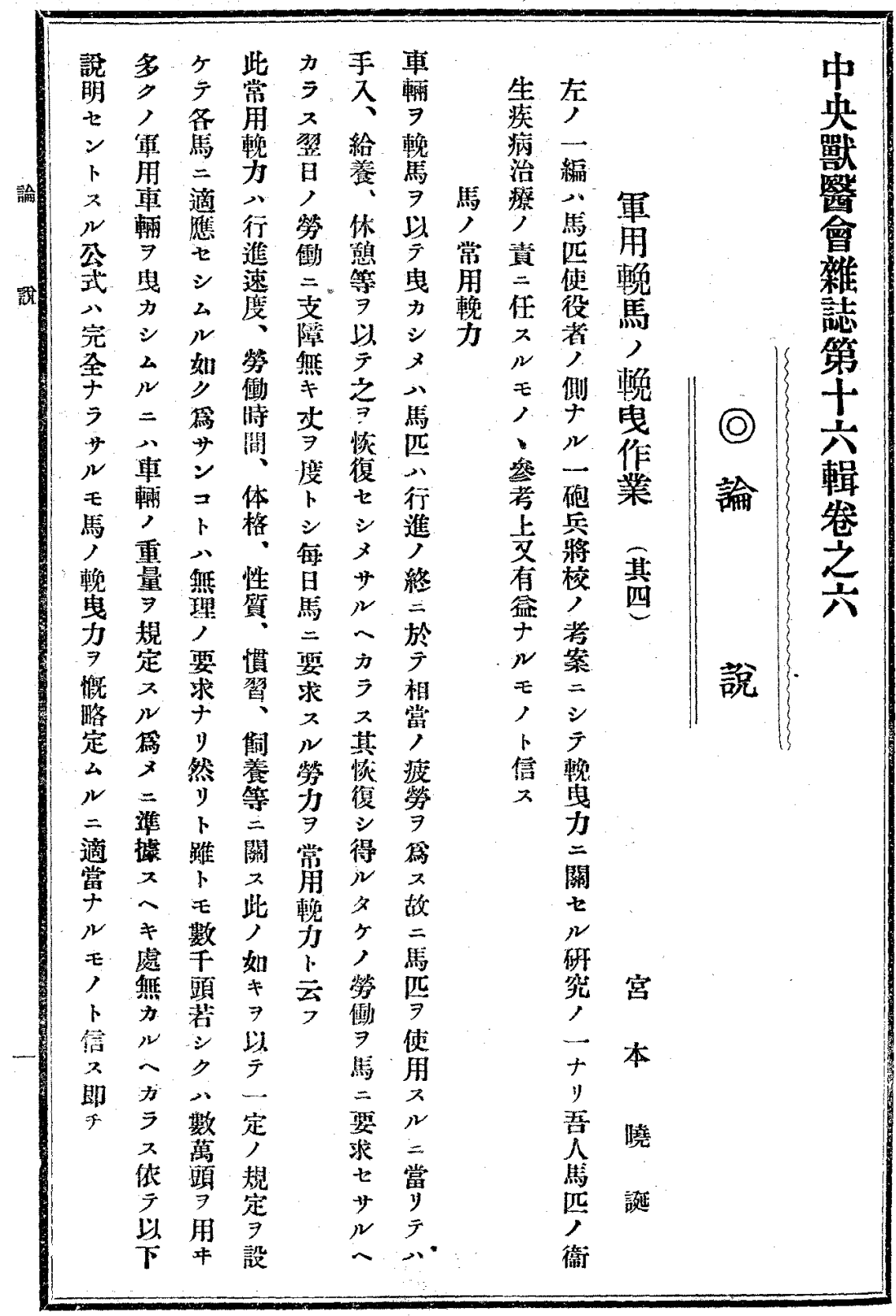


輯六十第誌雜會醫獸央中

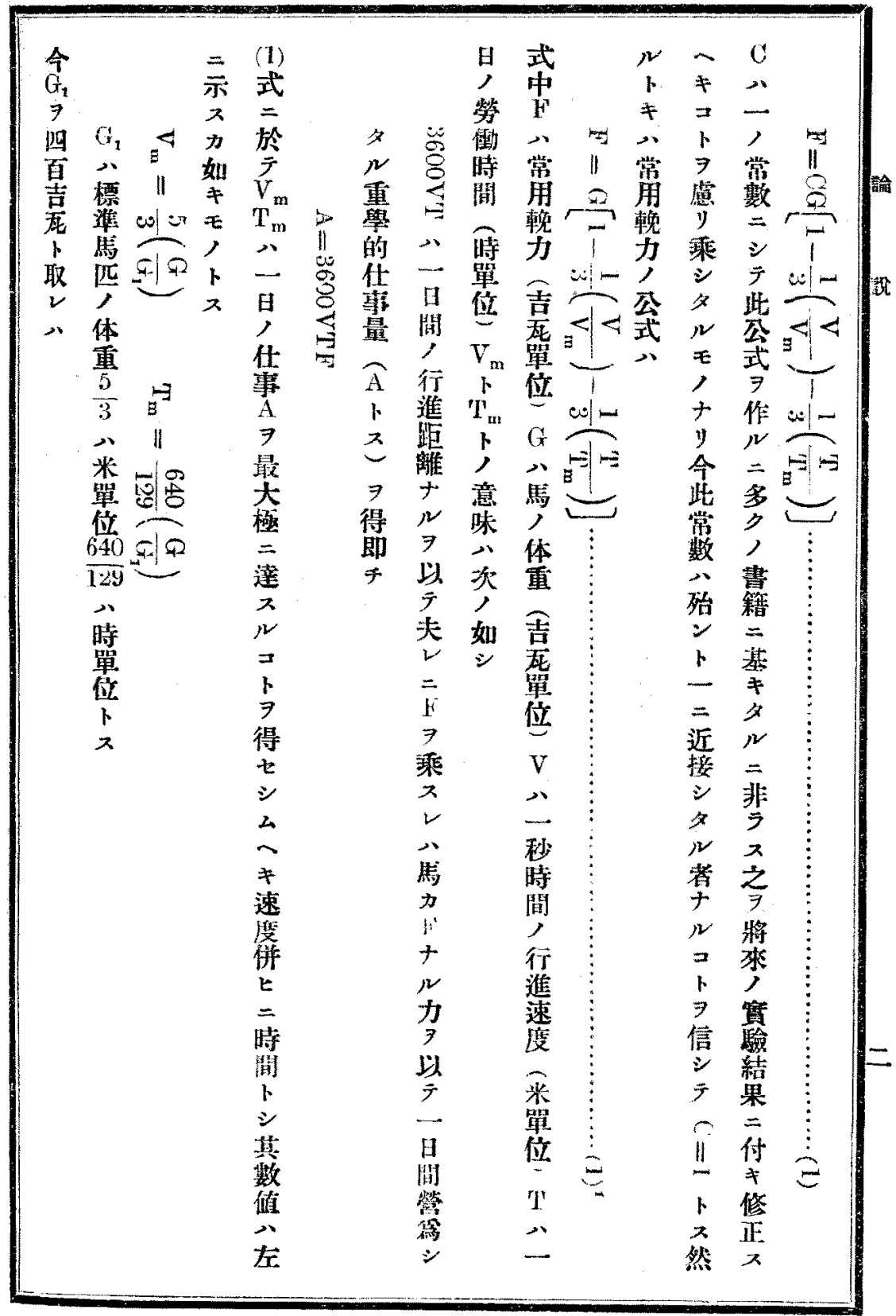




\section{輯六十第誌雜會 嘼央中}

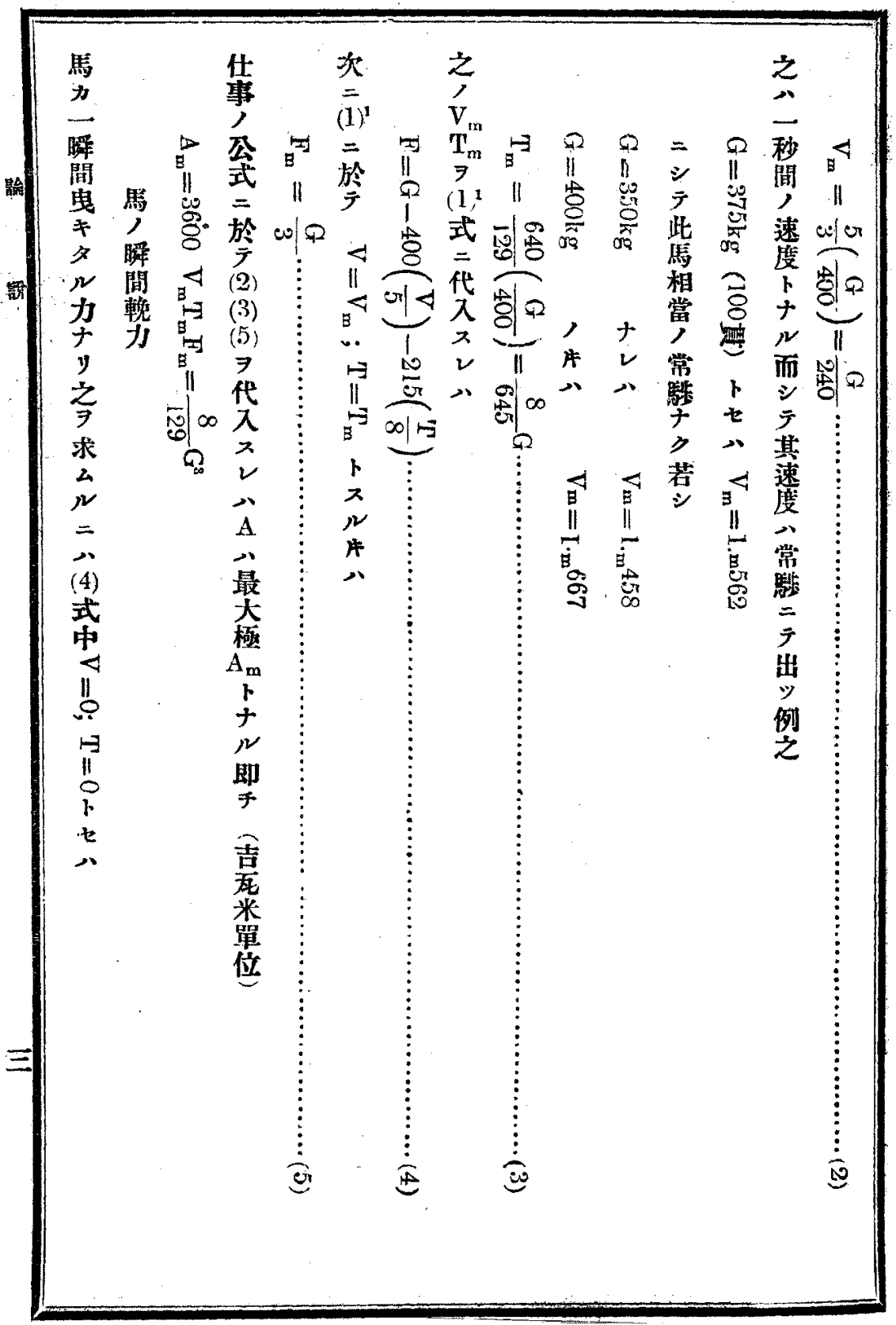


輯六十第誌程會醫獸央中

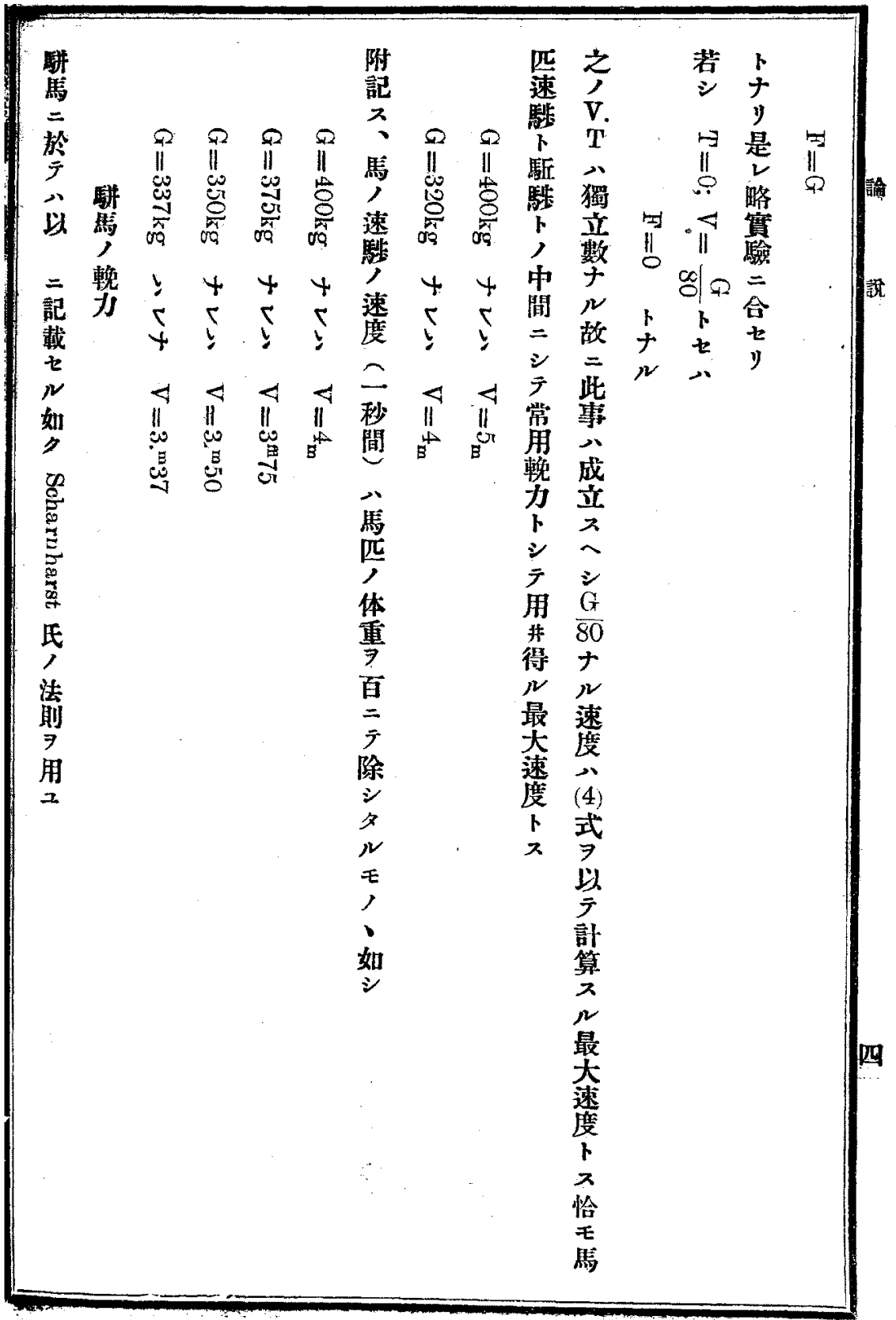


輯六十第誌雜會路嘼央中

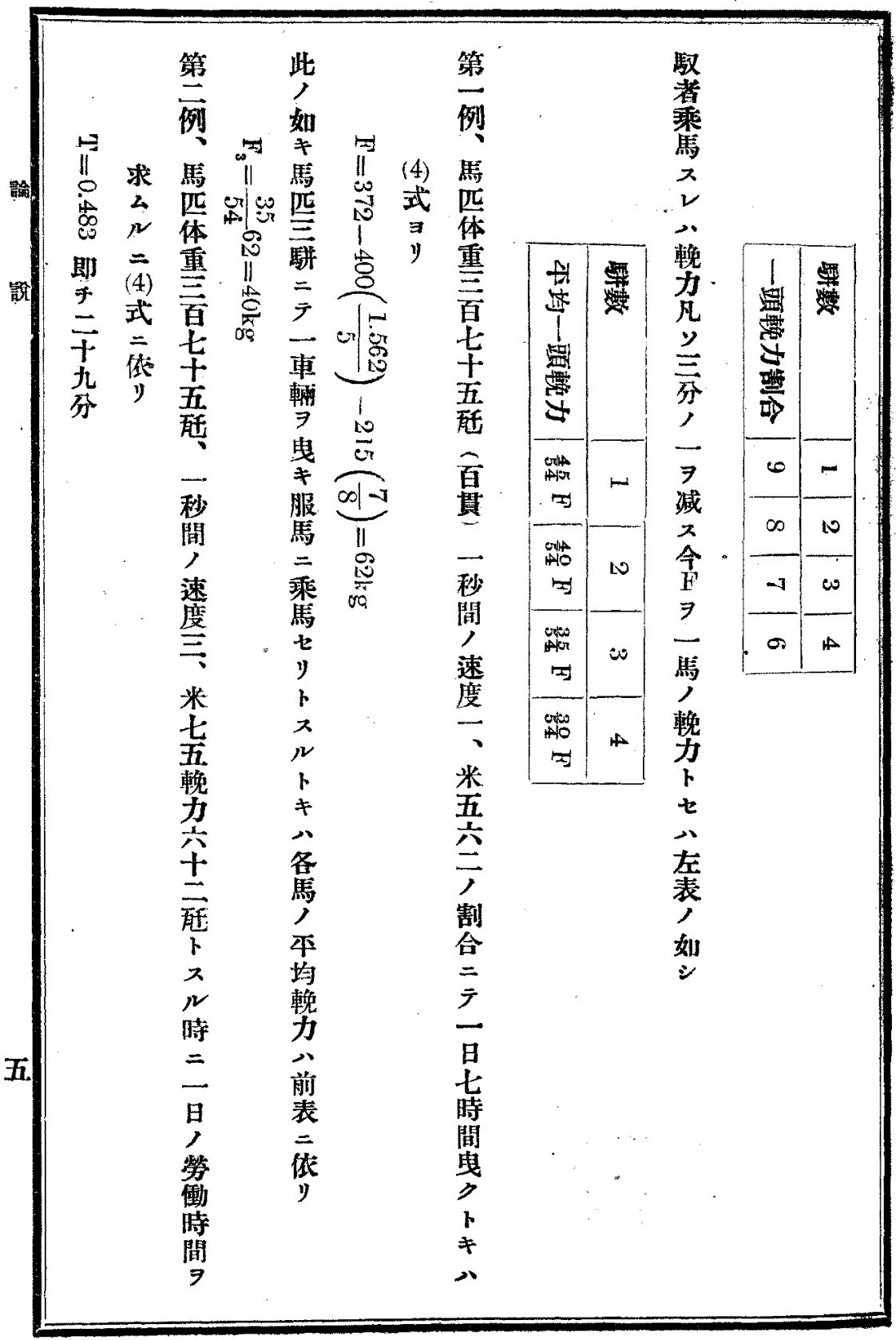




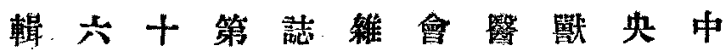

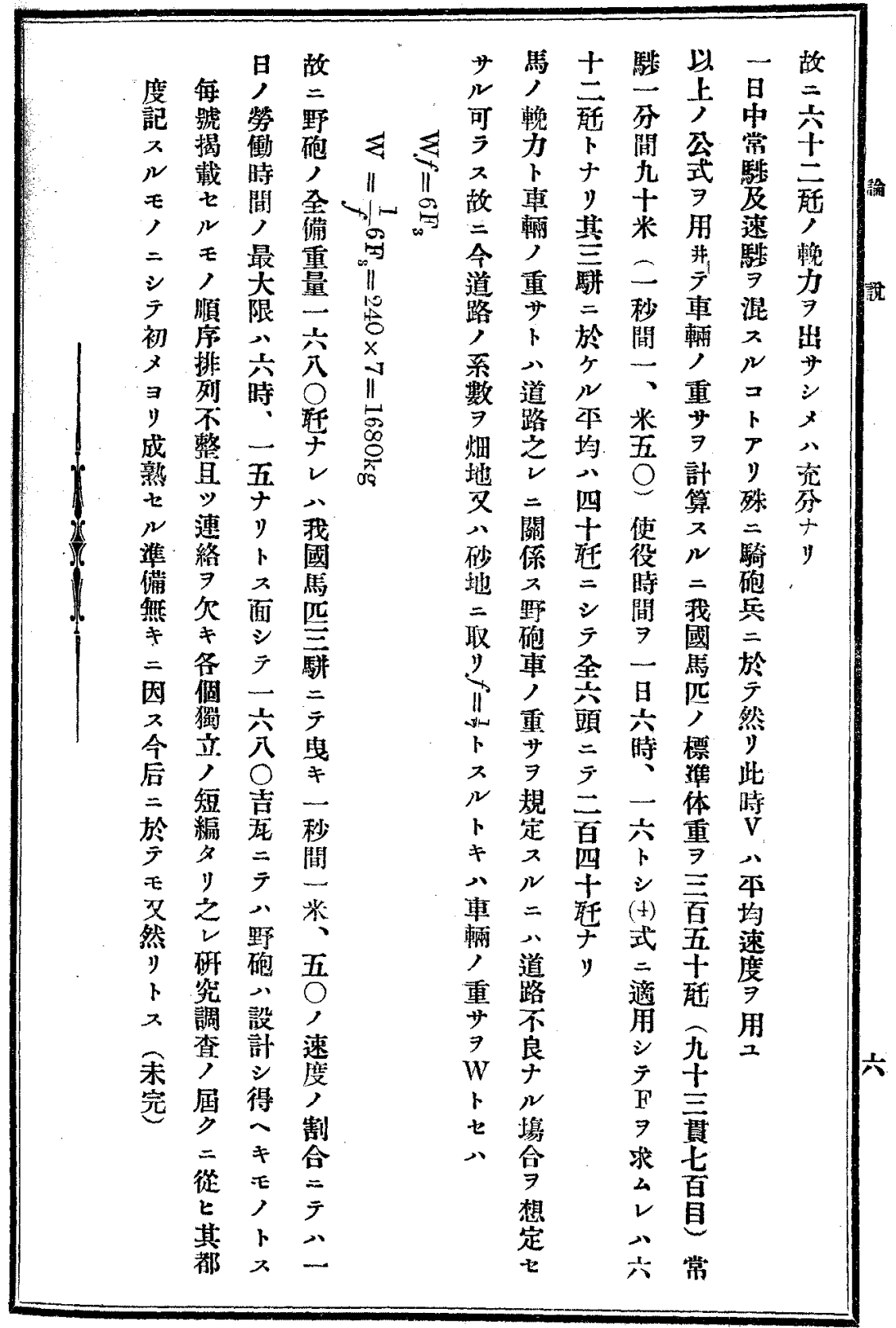

